\title{
Effect of auranofin on cytokine induced secretion of granule proteins from adherent human neutrophils in vitro
}

\author{
Johan Richter
}

\begin{abstract}
The effect of auranofin on granule protein secretion from neutrophils was investigated by a haemolytic plaque assay which can detect release of lactoferrin and myeloperoxidase from single adherent neutrophils. Lactoferrin secretion in response to $\boldsymbol{N}$-formyl-methionylleucyl-phenylalanine (fMLP) was enhanced at low $(0.25-1.0 \mu \mathrm{g} / \mathrm{ml})$ and inhibited at high concentrations of auranofin (50\% inhibition $\left(\right.$ IC $\left._{50}\right)$ at $\left.3.7 \mu \mathrm{g} / \mathrm{ml}\right)$. A similar biphasic effect was also seen on degranulation mediated by granulocyte-macrophage colony stimulating factor (GM-CSF) $\left(\mathrm{IC}_{50} 1.8 \mu \mathrm{g} / \mathrm{ml}\right)$. In contrast, exocytosis mediated by tumour necrosis factor was inhibited even at low concentrations of auranofin $\left(\mathrm{IC}_{50} 0.6 \mu \mathrm{g} / \mathrm{ml}\right)$. Secretion induced by phorbol 12-myristate 13-acetate and A23187 was only inhibited at very high auranofin concentrations $\left(I_{C_{0}} 10\right.$ and $8 \mu \mathrm{g} / \mathrm{ml}$ respectively). The effect of auranofin on myeloperoxidase secretion was also assessed and the $\mathbf{I C}_{50}$ values for the respective agents were as follows: tumour necrosis factor 0.7 $\mu \mathrm{g} / \mathrm{ml}$, fMLP $1.6 \mu \mathrm{g} / \mathrm{ml}$, and phorbol myristate acetate $7.6 \mu \mathrm{g} / \mathrm{ml}$. When neutrophils were preincubated with auranofin $(4 \mu \mathrm{g} / \mathrm{ml})$ and then exposed to fMLP, tumour necrosis factor, or GM-CSF in the absence of auranofin, lactoferrin release was enhanced if the preincubation time was short (one to three minutes) and inhibited when the time of preincubation was longer. It was concluded that auranofin, at concentrations achieved in the serum of patients, is a potent inhibitor of cytokine induced release of granule proteins from adherent neutrophils. This finding may be of clinical importance and shed light on the mechanism by which auranofin acts in rheumatoid arthritis.
\end{abstract}

Auranofin ( $S$-(triethylphosphoranediylaurio) 1thio- $\beta$-D-glucopyranose $2,3,4,6$-tetra-acetate) is a lipophilic gold compound that has become widely used in the treatment of rheumatoid arthritis. The exact mode of action of auranofin is still not known. The neutrophil granulocyte plays an important part in the inflammatory process-for example, in rheumatoid arthritis, and the effect of auranofin on neutrophil function has been studied by several investigators. Auranofin has been shown to inhibit phagocytosis, ${ }^{12}$ chemotaxis, ${ }^{2}$ release of lysosomal enzymes, ${ }^{12}$ the respiratory burst, and the generation of leukotrienes ${ }^{3}$ in neutrophils. In most of these studies the effect of auranofin was investigated on neutrophil functions stimulated with the chemotactic peptide $N$-formylmethionyl-leucyl-phenylalanine (fMLP) the complement factor C5A, or a non-physiological stimulus such as phorbol ester or calcium ionophore. Cytokines can activate neutrophils, ${ }^{45}$ and a pathogenetic role for cytokines in rheumatoid arthritis has been proposed. ${ }^{6}$ Tumour necrosis factor was detected in synovial tissues from patients with rheumatoid arthritis, but not in controls. ${ }^{7}$ Moreover, this factor has been found in synovial fluid and serum from patients with rheumatoid arthritis. ${ }^{8} \mathrm{~A}$ role for granulocyte-macrophage colony stimulating factor (GM-CSF) in rheumatoid synovitis has also been suggested. ${ }^{9}$ Considering these findings we decided to investigate whether auranofin could affect the tumour necrosis factor and GMCSF mediated effects on neutrophils. By using a haemolytic plaque assay to detect degranulation from single adherent neutrophils we have previously shown that both these cytokines induce secretion of granule proteins such as lactoferrin and myeloperoxidase. ${ }^{10}$ In this study the plaque assay was used to investigate the effect of auranofin on degranulation of adherent neutrophils induced by tumour necrosis factor and GM-CSF and to compare it with the effect on secretion mediated by fMLP, phorbol diester, and calcium ionophore.

\section{Materials and methods}

SPECIAL REAGENTS

Auranofin was obtained from Smith, Kline and French Laboratories, Philadelphia, Penn, USA. Recombinant human tumour necrosis factor was kindly supplied by Dr G R Adolf, ErnstBoehringer-Institut, Vienna, Austria. The preparation, assayed (by the supplier) by its cytolytic activity on L929 mouse fibroblast cells treated with actinomycin $\mathrm{D}$, contained $6 \times 10^{7}$ U/mg. Recombinant human GM-CSF was from Biogen, Geneva, Switzerland, and its specific activity was according to the supplier $3.4 \times 10^{8}$ $\mathrm{U} / \mathrm{mg}$. Antimyeloperoxidase and antilactoferrin were obtained by immunisation of rabbits with purified proteins. ${ }^{11}$ These antisera were highly specific and did not react with other neutrophil proteins, as judged by experiments with radial immunodiffusion. A23187, phorbol 12-myristate 13-acetate, and AMLP were from Sigma Chemical, St Louis, Mo, USA. Cytochalasin B was from Calbiochem-Behring, La Jolla, Calif, USA.

ISOLATION OF GRANULOCYTES

Blood was obtained from healthy volunteers. 
One part of $2 \%$ dextran (Pharmacia, Sweden) in $0.15 \mathrm{M} \mathrm{NaCl}$ was added to one part of heparinised blood. After red cell sedimentation the supernatant containing leucocytes was layered on top of Lymphoprep (Nyegaard, Oslo, Norway) and centrifuged, resulting in a pellet containing granulocytes and erythrocytes. After hypotonic lysis of the erythrocytes with sterile water for $30-45$ seconds the granulocytes were washed once in $0.15 \mathrm{M} \mathrm{NaCl}$ and once in Hanks's balanced salt solution (HBSS; Flow Laboratories, Irvine, Scotland) with $1 \%$ fetal bovine serum (Gibco, Paisley, Scotland). A Coulter counter was used for cell counting. Initially a Burker chamber was used for checking the Coulter counter readings and granulocyte purity, which was from 96 to $98 \%$. Viability was in excess of $97 \%$, as judged by trypan blue staining. The cells were allowed to equilibrate for at least 30 minutes in HBSS with $1 \%$ fetal bovine serum before use in the haemolytic plaque assay.

\section{COUPLING OF PROTEIN A TO SHEEP RED BLOOD CELLS}

Protein A (Pharmacia, Sweden) was coupled to sheep's red blood cells as previously described. ${ }^{12}$ In short, these cells, stored in Alsever's solution and aged one to three weeks, were washed three times in $0.15 \mathrm{M} \mathrm{NaCl}$. One part packed sheep's red blood cells was mixed with one part protein A $(0.5 \mathrm{mg} / \mathrm{ml}$ in $0.15 \mathrm{M} \mathrm{NaCl})$ and 10 parts $2.5 \times 10^{-4} \mathrm{M} \mathrm{CrCl}_{3}$ in $0.15 \mathrm{M} \mathrm{NaCl}$. The mixture was incubated at $30^{\circ} \mathrm{C}$ for one hour, washed once in $0.15 \mathrm{M} \mathrm{NaCl}$ and twice in HBSS, and kept at $4^{\circ} \mathrm{C}$. The cells were used within one week.

\section{HAEMOLYTIC PLAQUE ASSAY}

The haemolytic plaque assay was performed as described previously. ${ }^{10}$ Plastic dishes, $60 \mathrm{~mm}$ in diameter (Falcon Plastics, Oxnard, Calif, USA), were treated with a poly-L-lysine solution (25 $\mu \mathrm{g} / \mathrm{ml} \mathrm{0.15} \mathrm{M} \mathrm{NaCl}$; Sigma) for 15 minutes at room temperature. The dishes were rinsed once in $0.15 \mathrm{M} \mathrm{NaCl}$ and once in $\mathrm{HBSS}$ followed by
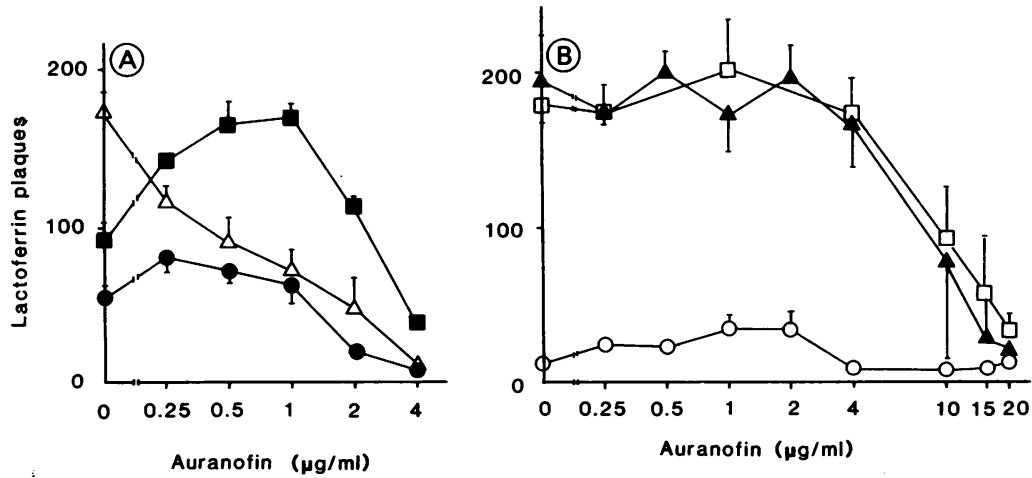

Figure 1 Effect of auranofin on lactoferrin secretion from adherent neutrophils. Neutrophils $\left(10^{6} / \mathrm{ml}\right.$ in Hanks's balanced salt solution with $1 \%$ fetal bovine serum) were incubated at $37^{\circ} \mathrm{C}$ for five minutes with the indicated concentrations of auranofin and then added to the plaque assay system with the same concentrations of auranofin. (A) To these cells was added I inM tumour necrosis factor $(\triangle \wedge \triangle), I$ nM granulocyte-macrophage colony stimulating factor (O) or $100 \mathrm{nM}$ N-formyl-methiomyl-leucyl-phenylalanine ( $\square)$. (B) To these cells was added $1 \mu M$ A23187 ( 1 - $), 10 \mathrm{ng} / \mathrm{ml}$ phorbol myristate acetate $\left(\begin{array}{l}\square- \\ -\end{array}\right)$, or no stimulus $(\mathrm{O}-\mathrm{O})$. The values given represent the mean $(S E M)$ from at least three separate experiments. SEM values not shown in the figure fall within the outline of the corresponding symbol. addition of $1 \mathrm{ml}$ of a $1 \%$ suspension of protein A-sheep's red blood cells in HBSS. After 15 minutes' incubation at $4^{\circ} \mathrm{C}$ surplus protein $\mathrm{A}$ sheep's red blood cells was poured off, followed by addition of antilactoferrin (1/2560) or antimyeloperoxidase (1/320) and guinea pig complement (1/100, Flow Laboratories), granulocytes, and a stimulatory agent dissolved in $1 \mathrm{ml}$ of HBSS. About 330 granulocytes were added to each dish. The dishes were incubated for two hours at $37^{\circ} \mathrm{C}$ and then fixed with a $5 \%$ solution of glutaraldehyde in phosphate buffer and stored at $4^{\circ} \mathrm{C}$ until the haemolytic plaques were counted under a microscope. A plaque was defined as a round area in which all the sheep's red blood cells had been lysed. In questionable cases a higher magnification was used to identify the single granule protein secreting neutrophil in the middle of the haemolytic zone before a plaque was actually defined as a plaque.

\section{Results}

\section{EFFECT OF AURANOFIN ON LACTOFERRIN} SECRETION

Neutrophils $\left(10^{6} / \mathrm{ml}\right.$ in HBSS with $1 \%$ fetal bovine serum) were incubated at $37^{\circ} \mathrm{C}$ for five minutes with various concentrations of auranofin, then added to the plaque assay system with the same concentration of auranofin and exposed to either tumour necrosis factor (1 nmol/l), GM-CSF (1 nmol/l), fMLP (100 $\mathrm{nmol} / \mathrm{l}), \mathrm{A} 23187$ (1 $\mu \mathrm{mol} / \mathrm{l})$, phorbol myristate acetate $(10 \mathrm{ng} / \mathrm{ml})$, or no stimulus. Figure 1 shows the results obtained. At low concentrations $(0.25-1.0 \mu \mathrm{g} / \mathrm{ml})$ auranofin enhanced lactoferrin plaque formation in response to fMLP and GM-CSF. At higher concentrations $(2.0-4.0 \mu \mathrm{g} / \mathrm{ml})$, however, an inhibitory effect of auranofin was seen. Lactoferrin secretion induced by tumour necrosis factor, on the other hand, was not enhanced by auranofin, and an inhibitory effect was noted even at $0.25 \mu \mathrm{g} / \mathrm{ml}$. The inhibitory effect on degranulation induced by phorbol myristate acetate and A23187 was only detected at auranofin concentrations of 10 $\mu \mathrm{g} / \mathrm{ml}$ or higher. The table shows the concentrations of auranofin resulting in $50 \%$ inhibition $\left(\mathrm{IC}_{50}\right)$ of the effect of the different secretagogues used.

KINETICS OF AURANOFIN EFFECT ON LACTOFERRIN SECRETION

Neutrophils $\left(10^{6} / \mathrm{ml}\right.$ in HBSS with $1 \%$ fetal bovine serum) were incubated at $37^{\circ} \mathrm{C}$ with

Concentrations of auranofin at which lactoferrin and myeloperoxidase secretion expressed as plaque formation was myeloperoxidase secretion
reduced by $50 \%\left(I C_{50}\right)$

\begin{tabular}{lcl}
\hline $\begin{array}{l}\text { Stimulatory } \\
\text { agent }\end{array}$ & $\begin{array}{l}\text { Lactoferrin } \\
\text { secretion } \\
(\mu g / m l)\end{array}$ & $\begin{array}{l}\text { Myeloperoxidase } \\
\text { secretion } \\
(\mu g / m l)\end{array}$ \\
\hline TNF & 0.6 & $0 \cdot 7 \dagger$ \\
GM-CSF & 1.8 & - \\
fMLP & $3 \cdot 7$ & $1 \cdot 6$ \\
PMA & 10 & $7 \cdot 6$ \\
A23187 & 8 & -
\end{tabular}

*TNF=tumour necrosis factor; GM-CSF = granulocyte-macrophage colony stimulating factor; $f M L P=N$-formyl-methionylphage colony stimulating factor; fMLP $=N$-formyl-meth †Does not take into account the peak seen at $2 \mu \mathrm{g} / \mathrm{ml}$ (fig 3). 


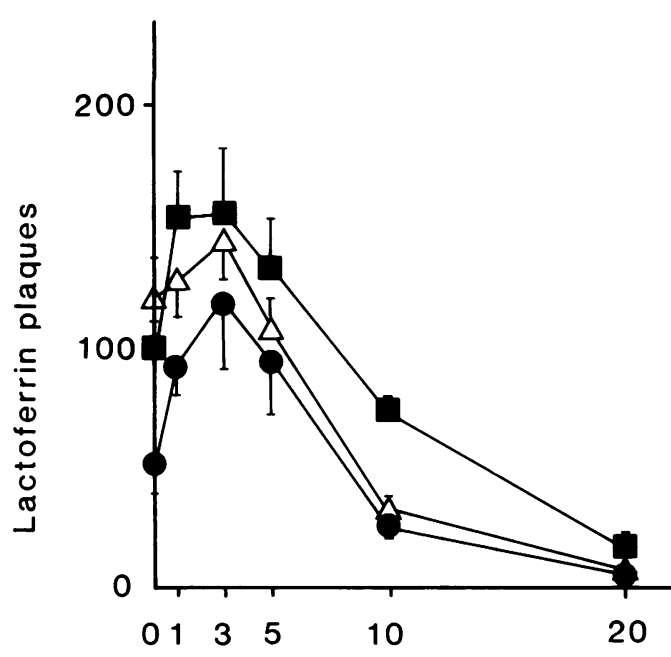

Preincubation with auranofin

(minutes)

Figure 2 Kinetics of auranofin effect on lactoferrin secretion. Neutrophils $\left(10^{\circ} / \mathrm{ml}\right.$ in Hanks's balanced salt solution with $1 \%$ fetal bovine serum) were incubated at $37^{\circ} \mathrm{C}$ with auranofin $(4 \mu \mathrm{g} / \mathrm{ml})$ for the indicated periods of time, added to the degranulation assay, without auranofin and fetal bovine serum, and stimulated with 1 nM tumour necrosis factor $(\triangle \stackrel{\triangle}{\longrightarrow}, 1 \mathrm{nM}$ granulocyte-macrophage colony stimulating factor (-), or $100 \mathrm{nM} \mathrm{N}$-formylmethionyl-leucyl-phemylalanine (-). The values given represent the mean (SEM) from three separate experiments. $S E M$ values not shown in the figure fall within the outline of the corresponding symbol.

auranofin $(4 \mu \mathrm{g} / \mathrm{ml})$ for various periods of time. The cells were then added to the degranulation assay, without auranofin, and incubated with tumour necrosis factor ( $1 \mathrm{nmol} / \mathrm{l}), \mathrm{GM}-\mathrm{CSF}$ (1 $\mathrm{nmol} / \mathrm{l})$, or fMLP $(100 \mathrm{nmol} / \mathrm{l})$. Short periods of preincubation (one and three minutes) with auranofin resulted in enhancement of lactoferrin secretion mediated by all three agents, whereas preincubation with auranofin for 10 or 20 minutes inhibited enzyme release (fig 2 ).

\section{EFFECT OF AURANOFIN ON MYELOPEROXIDASE SECRETION}

Neutrophils $\left(10^{6} / \mathrm{ml}\right)$ were incubated at $37^{\circ} \mathrm{C}$ for five minutes with various concentrations of auranofin and then added to the plaque assay system with the same concentration of auranofin and cytochalasin $B(0.3 \mu \mathrm{g} / \mathrm{ml})$. In the plaque assay system either tumour necrosis factor $(10 \mathrm{nmol} / \mathrm{l}), \mathrm{fMLP}(100 \mathrm{nmol} / \mathrm{l})$, phorbol myristate acetate $(10 \mathrm{ng} / \mathrm{ml})$, or no stimulus was added (fig 3). The effect of auranofin on myeloperoxidase secretion induced by phorbol myristate acetate was almost identical with the effect on lactoferrin secretion. Degranulation of myeloperoxidase mediated by IMLP was enhanced at low $(0.25-0.50 \mu \mathrm{g} / \mathrm{ml})$ and inhibited at high $(1.0-4.0 \mu \mathrm{g} / \mathrm{ml})$ concentrations of auranofin. The tumour necrosis factor effect was progressively inhibited except that at 2 $\mu \mathrm{g} / \mathrm{ml}$ of auranofin there was a significant increase in secretion of myeloperoxidase as compared with $1 \mu \mathrm{g} / \mathrm{ml}$. This increase was seen in each of four separate experiments. The table shows the concentrations of auranofin resulting in $50 \%$ inhbition $\left(\mathrm{IC}_{50}\right)$ of the effect of the different secretagogues used.

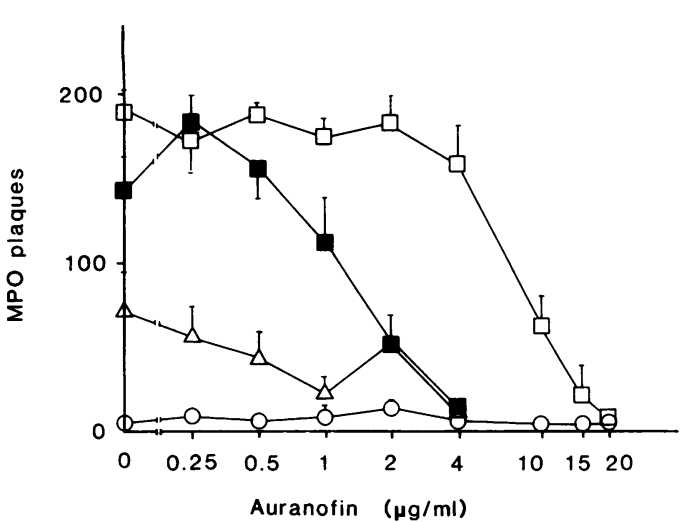

Figure 3 Effect of auranofin on myeloperoxidase (MPO) secretion from adherent neutrophils. Neutrophils $\left(10^{6} / \mathrm{ml}\right.$ in Hanks's balanced salt solution with $1 \%$ fetal bovine serum) were incubated at $37^{\circ} \mathrm{C}$ for five minutes with the indicated concentrations of auranofin and then added to the plaque assay system with the same concentration of auranofin and cytochalasin $B(0.3 \mu \mathrm{g} / \mathrm{ml})$. Subsequently, the cells were exposed to $10 \mathrm{nM}$ tumour necrosis factor ( $\triangle \triangle), 100 \mathrm{nM}$ $\mathrm{N}$-formyl-methionyl-leucyl-phenylalanine ( $10 \mathrm{ng} / \mathrm{ml}$ phorbol myristate acetate ( $\square-\square)$, or no stimulus $(\mathrm{O}-0)$. The values given represent the mean (SEM) from four separate experiments. SEM values not shown in the figure fall within the outline of the corresponding symbol.

\section{Discussion}

Adherence of neutrophils to a surface has been suggested to play an important part in activation of these cells by cytokines, ${ }^{13} 14$ which makes the plaque assay suitable for studying the effects of cytokines on neutrophil degranulation. It should be noted that the haemolytic plaque assay is semiquantative as it measures the fraction of adherent neutrophils undergoing exocytosis but not the amount of protein secreted. On the other hand, the assay makes it possible to study secretion at the single cell level and only a limited number of cells is required.

The effect of auranofin on release of granule proteins from neutrophils has been investigated before. ${ }^{2} \mathrm{~A}$ biphasic response was described for fMLP induced secretion of lysozyme (a protein found in both primary and secondary granules) and $\beta$-glucuronidase (solely located in primary granules). These results are well in accordance with our findings of enhancement of both lactoferrin and myeloperoxidase secretion at low but inhibition at higher concentrations of auranofin. In the previous work auranofin was found not to affect enzyme release in response to calcium ionophore in the concentration range $1-4 \mu \mathrm{g} / \mathrm{ml} .^{2}$ This also correlates closely with our observation that significant inhibition of exocytosis mediated by calcium ionophore only occurred at high concentrations of auranofin.

The effect of auranofin on neutrophil functions activated by cytokines has, to our knowledge, not been investigated previously. Our findings of inhibitory effects of auranofin, particularly on tumour necrosis factor induced, but also GM-CSF induced degranulation at low concentrations are of clinical interest but may also help to explain the signal-transduction mechanisms taking place. The serum concentrations of auranofin obtained after long term oral administration of the drug are in the approximate rate $1.5-3.5 \mu \mathrm{g} / \mathrm{ml}^{2}$ Enzyme release in response to $\mathrm{AMLP}$, phorbol myristate 
acetate, or A23187 is not significantly inhibited within this concentration range (present data), ${ }^{2}$ whereas degranulation induced both by tumour necrosis factor and GM-CSF is inhibited by more than $50 \%$. In view of this, and the proposed role of cytokines in rheumatoid arthritis, ${ }^{6}$ it might be more relevant to investigate the effect of auranofin on neutrophils incubated with cytokines as compared with phorbol esters, ionophores, and even fMLP in order to understand how auranofin affects the inflammatory process in rheumatoid arthritis.

The biphasic response to auranofin was also noted in the kinetic experiments performed. Preincubation of neutrophils with auranofin for one to three minutes before addition of one of the receptor mediated agonists tumour necrosis factor, GM-CSF, or fMLP enhanced the secretory response, whereas preincubation for $10-20$ minutes resulted in an inhibition of degranulation. In a previous study the inhibitory effect was found to be almost complete after five minutes, ${ }^{15}$ but the experiments were carried out in medium devoid of serum or albumin. Cells take up auranofin more slowly in the presence of serum ${ }^{16}$ and this might account for the longer preincubation time for the inhibitory effect to occur found in our study, in which cells were incubated with auranofin in the presence of $1 \%$ fetal bovine serum.

The exact mode of action of auranofin at the cellular level is not understood. It has been suggested that the effect on neutrophils is mediated through inhibition of protein kinase C. ${ }^{17}$ At a concentration of $20 \mu \mathrm{mol} / 1$ (13.6 $\mu \mathrm{g} / \mathrm{ml}$ ) auranofin was reported to inhibit superoxide production and translocation of protein kinase $\mathrm{C}$ from the cytosol to the plasma membrane in response to phorbol myristate acetate, an activator of protein kinase $C$. In the present study auranofin at a concentration of at least 10 $\mu \mathrm{g} / \mathrm{ml}$ was required to show an effect on degranulation induced by phorbol myristate acetate. A concentration of less than $1 \mu \mathrm{g} / \mathrm{ml}$ was needed to inhibit substantially lactoferrin secretion induced by tumour necrosis factor. Therefore, it is unlikely that protein kinase $C$ is the point of action for auranofin for degranulation in neutrophils mediated by tumour necrosis factor. This is further supported by the fact that so far no involvement of protein kinase $\mathrm{C}$ in tumour necrosis factor signal-transduction in neutrophils has been shown. ${ }^{18}$ Thus at clinical concentrations of auranofin it is more likely that the action is exerted at some other point in the signal-transduction process. The finding that auranofin at the same dose enhanced lactoferrin secretion induced by GMCSF and inhibited that induced by tumour necrosis factor indicates that the two cytokines exert their effects through distinct signaltransduction pathways.

In conclusion, we have found that auranofin inhibits tumour necrosis factor and GM-CSF induced granule protein secretion from adherent human neutrophils at concentrations that are close to those seen in the serum of patients treated with auranofin. In the light of the proposed role of cytokines in rheumatoid arthritis this finding may help to explain the clinical effects of auranofin.

The sheep red blood cells were kindly supplied by the depart ment of microbiology, University of Lund, Sweden.

The author thanks Karin Vegas for excellent technica assistance, Professor Inge Olsson, who served as scientific adviser, and Professor Frank Wollheim for reviewing the manuscript. This work was supported by the Swedish Society of Medicine, the Alfred Österlund Foundation, and the Medical Faculty of Lund.

1 Dimartino M J, Walz D T. Inhibition of lysosomal enzyme release from rat leukocytes by auranofin. Inflammation 1977; 2: 131-42.

2 Hafström I, Uden A M, Palmblad J. Modulation of neutrophi functions by auranofin. Scand $\mathcal{F}$ Rheumatol 1983; 12 : 97-105.

3 Herlin T, Fogh K, Christiansen N O, Kragballe K. Effect of auranofin on eicosanoids and protein kinase $\mathrm{C}$ in human neutrophils. Agents Actions 1989; 28: 121-9.

4 Shalaby M R, Aggarwal B B, Rinderknecht E, Svedersky L P, Finkle B S, Palladino Jr M A. Activation of human polymorphonuclear functions by interferon-gamma and polymorphonuclear functions by interferon-gamma a
tumor necrosis factors. $\mathcal{F}$ Immunol 1985; 135: 2069-73.

5 Klebanoff S J, Vadas M A, Harlan J M, et al. Stimulation of neutrophils by tumor necrosis factor. $\mathcal{F}$ Immunol 1986; 136 : $4220-5$.

6 Talal N, Flescher E. Rheumatoid arthritis. An editorial perspective based on cytokine imbalance. $\mathcal{f}$ Autoimmun 1988; 1: 309-17.

7 Husby G, Williams Jr R C. Synovial localization of tumor necrosis factor in patients with rheumatoid arthritis. f Autoimmun 1988; 1: 363-71.

8 Saxne T, Palladino Jr M A, Heinegård D, Wollheim F A. Detection of tumor necrosis factor alpha but not tumor necrosis factor beta in rheumatoid arthritis synovial fluid necrosis factor beta in rheumatoid arthritis syn

9 Alvaro-Gracia J M. Firestein G S, Xu W D, Taetle R Zvaifler N J. GM-CSF is a major macrophage activating factor (MAF) in rheumatoid synovitis [Abstract]. Proceed ings of the American Rheumatism Association 1988: S27.

10 Richter J, Andersson T, Olsson I. Effect of tumor necrosis factor and granulocyte/macrophage colony-stimulating factor on neutrophil degranulation. F Immunol 1989; 142: 3199-205.

11 Olofsson T, Olsson I, Venge P, Elgefors B. Serum myeloperoxidase and lactoferrin in neutropenia. Scandinavian fournal of Haematology 1977; 18: 73-80.

12 Gronowicz E, Coutinho A, Melchers F A. A plaque-assay for all cells secreting Ig of a given type or class. Eur $\mathcal{Y}$ Immunol all cells secreting

13 Nathan $C$ F. Neutrophil activation on biological surfaces. f Clin Invest 1987; 80: 1550-60.

14 Nathan C F. Respiratory burst in adherent human neutrophils: triggering by colony-stimulating factors CSF-GM and CSF-G. Blood 1989; 73: 301-6.

15 Hafström I, Seiligmann B E, Friedman M M, Gallin J I Auranofin affects early events in human polymorphonuclear neutrophil activation by receptor-mediated stimuli. f Immunol 1984; 132: 2007-14.

16 Herrlinger J D, Alsen C, Beress R, Hecker U, Weikert W Distribution of gold in serum erythrocytes and white blood cells after in vitro incubation and during chrysotherapy 81-9.

17 Parente J E, Walsh M P, Girard P R, Kuo J F, Ng D S Wong $K$. Effects of gold coordination complexes on neutrophil function are mediated via inhibition of protein kinase C. Mol Pharmacol 1989; 35: 26-33.

18 Berkow R L, Dodson M R. Biochemical mechanisms involved in the priming of neutrophils by tumor necrosis factor. F Leukoc Biol 1988; 44: 345-52. 